\title{
The Economics of Battery Storage for Residential Solar Customers in Southern California
}

\author{
John B. Broughton, Prashanth U. Nyer*, Candace E. Ybarra \\ Argyros School of Business \& Economics, Chapman University, Orange, CA, USA \\ Email: broughto@chapman.edu, ^nyer@chapman.edu, cybarra@chapman.edu
}

How to cite this paper: Broughton, J. B., Nyer, P. U., \& Ybarra, C. E. (2021). The Economics of Battery Storage for Residential Solar Customers in Southern California. American Journal of Industrial and Business Management, 11, 924-932. https://doi.org/10.4236/ajibm.2021.118056

Received: July 21, 2021

Accepted: August 22, 2021

Published: August 25, 2021

Copyright $\odot 2021$ by author(s) and Scientific Research Publishing Inc. This work is licensed under the Creative Commons Attribution International License (CC BY 4.0).

http://creativecommons.org/licenses/by/4.0/

\begin{abstract}
Battery storage coupled with solar panels became a consideration after the original net metering program in California (NEM 1.0) ended and gave way to the current net metering program (NEM 2.0). Under NEM 2.0, battery storage gives customers under time-of-use (TOU) rate plans the ability to store the excess electrical energy generated by their panels during sunlight hours (when electricity usage and resale rates are low) and then use that energy in the evening when rates are significantly higher. This reduces the amount of expensive electricity that the customer would have to purchase from the grid. It is widely expected that the current net metering program in California will be replaced by a more restrictive and much less financially attractive program when NEM 3.0 goes into effect in early 2022. The impending introduction of NEM 3.0 has accelerated the rate at which homeowners are installing solar panel arrays and battery storage. In this paper we examine the economics of installing battery storage for residential customers and examine whether battery storage makes financial sense. We use public data to model the electricity bills for an average sized residential customer in southern California and examine how much money this customer can save using battery storage under the current rate plans.
\end{abstract}

\section{Keywords}

Solar Panels, Battery, Powerwall, Net Metering, NEM, Rate Plan, Tariff, Time of Use, Savings, California

\section{Introduction}

Starting in 2017, there has been a sharp increase in the number of residential *Corresponding author. 
customers in California coupling battery storage with their new or existing solar panel systems (see Figure 1). The timing of this surge can be partly attributed to the availability of affordable, maintenance free Lithium-ion based battery technology from Tesla and its competitors. Tesla's Powerwall was first available in May 2015 with production volumes ramping up in the following months. Another factor that could have contributed to the sharp uptick in battery installations starting in 2017 was the ending of the original net metering program. The relevance of battery storage, and how it could potentially help customers save on their electricity bills, and thus the contribution of this research, can be appreciated only with some understanding of how net metering works.

California is one of several states with a net metering program for customers who have solar panel installations. The net metering program that a customer is enrolled in specifies how the customer will be compensated for excess solar generated electricity that the customer exports to the grid during sunlight hours. The first net metering program (NEM 1.0) was available to customers who went solar up to 2016-2017. The exact date on which NEM 1.0 ended varied by the utility company, with San Diego Gas and Electric (SDG \& E) ending NEM 1.0 in June 2016, Pacific Gas and Electric Company (PG \& E) ending its program in November 2016, and Southern California Edison (SCE) ending its program in July 2017. Under NEM 1.0 solar customers were permitted to remain on a flat rate plan where one kiloWatt hour ( $\mathrm{kWh}$, a unit of electricity corresponding to the energy consumption of a 1000 watt device used for one hour) cost the same regardless of the time of day. Further, one kWh of excess solar energy exported to the grid during sunlight hours was compensated for at exactly the same rate that the customer paid for one $\mathrm{kWh}$ of electricity imported from the grid in the evening. Thus, under NEM 1.0, solar customers could treat the grid as an infinitely large and $100 \%$ efficient battery storage device. Customers who went solar under NEM 1.0 are grandfathered into that program for 20 years. Nyer, Broughton and Ybarra (2019) found that it was very financially beneficial for customers to go solar under NEM 1.0.

NEM 2.0, which went into effect after NEM 1.0 ended, forced new solar customers into time of use (TOU) plans where electricity rates varied by time of

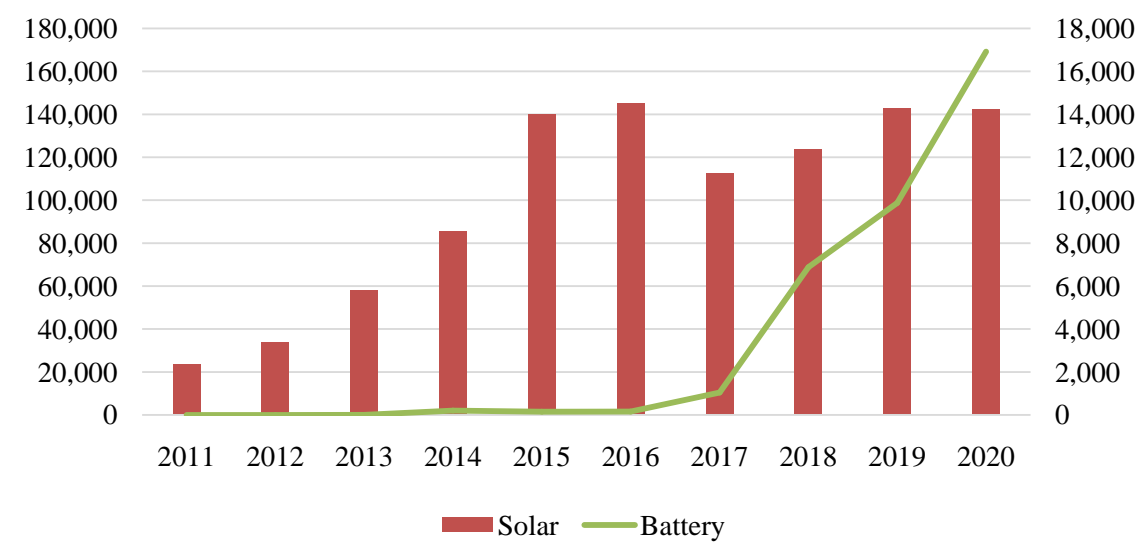

Figure 1. Number of solar panel (left) and battery storage (right) installations by year. 
day. Rates are typically low during peak sunlight hours and much higher during peak demand hours in the evening. For example, during the weekdays of July 2021, the rate for electricity for SCE customers on the TOU 4-9 plan was only $\$ 0.27$ per kWh between 8:00AM and 4:00PM, while the rate increased to $\$ 0.43$ per kWh between 4:00PM and 9:00PM. While solar customers under NEM 2.0 can export excess solar energy to the grid, they are compensated for the exports at much lower rates compared to the rates that the customers pay for electricity that they purchase from the grid in the evening hours when electricity demand is higher. In addition, NEM 2.0 introduced some additional fees to solar customers under this program. Nyer, Ybarra and Broughton (2019) examined the economics of solar panel installations under the various rate plans available under NEM 1.0 and NEM 2.0 and concluded that while NEM 2.0 was not as financially attractive to customers as NEM 1.0, it still made financial sense for customers to go solar under NEM 2.0.

Figure 1 presents the number of residential solar panel and battery storage installations in the PG \& E, SCE and SDGE service areas for 2011-2020. The data come from California Distributed Generation Statistics (Distributed Generation Interconnection Program Data, 2021), a database authorized by the California Public Utilities Commission (CPUC). The column graph depicts the number of residential accounts getting solar panels installed (with the corresponding scale on the left), while the line graph shows the number of residential accounts getting battery storage installed (with the corresponding scale on the right.) The sharp drop in the number of solar installations (from 144,840 installations in 2016 , to 112,570 in 2017) is likely due to the end of NEM 1.0 which undoubtedly incentivized customers who were considering a solar installation to accelerate the process and install the panels before NEM 1.0 ended (between June 2016 and July 2017 depending on the utility).

The end of NEM 1.0 also saw a sudden increase in battery installations. As we suggested previously, this could have been partly associated with increased battery availability and consumer awareness of maintenance free and relatively affordable Lithium-ion based batteries from Tesla and its competitors. It could also have been caused by the desire of customers on TOU plans to reduce electricity expenses by storing cheap solar electricity generated during sunlight hours (rather than selling it to the grid at a low price) and then using that energy later in the evening when the rates are significantly higher (and thus reducing the amount of expensive electricity purchased from the grid). However, does battery storage make financial sense considering only the ability to substitute solar generated electricity for expensive electricity purchased from the grid during evening hours? In this paper we examine the economics of battery storage under the current rate plans available to residential customers of SCE. The findings should also apply to customers of the other two California investor-owned utilities (IOU).

While the Tesla Powerwalls are the best-known residential battery storage solution, they are by no means the only battery storage system available to con- 
sumers. LG, Enphase, sonnenCore and other businesses provide alternatives. However, on an installed cost per kWh, the Powerwall 2 offers a good value despite recent price hikes. While we will use a Tesla Powerwall 2 as the basis of our analysis, the broad findings should be applicable to other battery brands. The Tesla Powerwall 2 costs approximately $\$ 13,200$ including installation, which nets to $\$ 9768$ after the $26 \%$ federal tax credit. The battery has a usable energy capacity of $13.5 \mathrm{kWh}$, and a $90 \%$ round-trip efficiency. It carries a warranty of 10 year or $37.8 \mathrm{MWh}$ throughput.

\section{Data}

We have estimated the annual electricity bills for a hypothetical Orange County based home located in ZIP code 92867 that uses $7411 \mathrm{kWh}$ of electricity annually (the average annual residential electricity use per household for that ZIP code in 2018-2019 (Southern California Edison, 2021a)) under different current rate plans using the methodology established by Nyer et al., (Nyer, Ybarra, \& Broughton, 2019; Nyer, Broughton, \& Ybarra, 2019). To do this, we estimated the energy produced by the solar panels at this home during every hour of the year (based on data from PVWatts (https://pvwatts.nrel.gov/), estimated the energy used by this home during every hour of the year (based on data from Southern California Edison), and thus estimated the net consumption of electricity for this customer for every hour during the year. Finally, we used the published rate plans from Southern California Edison (2021b) to calculate the annual electricity bills. We separately report electricity bills with and without a solar panel array facing south designed to produce exactly $7411 \mathrm{kWh}$ a year, and with and without one Tesla Powerwall 2 battery. Further, we estimate the electricity bills for four hypothetical load profiles (see Figure 2 for some of these load profiles.) The annual electricity consumption for all load profiles was set to $7411 \mathrm{kWh}$. The purpose of introducing multiple load profiles is to make the analysis and the conclusions more robust and generalizable. The four load profiles are described below.

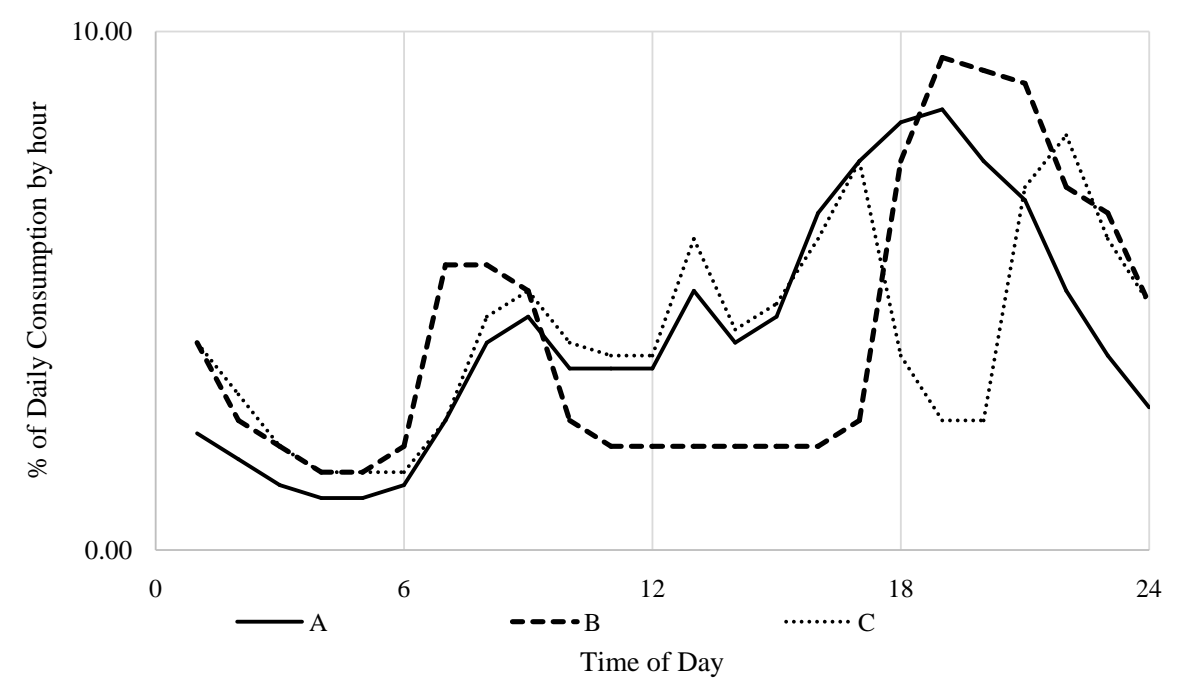

Figure 2. Load profiles. 
A) Adults working from home. These households typically have someone home throughout the day. As such, during the summer months air-conditioners get turned on earlier in the afternoon. Once the house is cooled, the electrical load will be relatively lower during the later evening hours.

B) Adults working outside the home with no children. These homes will typically be unoccupied during the work-day and will see a sharp increase in electricity use in the early evening hours in summer when the residents return from work.

C) Adults working from home but away from 5PM to 8PM. These could be individuals who work from home and attend school or run errands in the evening. These households typically have a usage pattern similar to load profile A with the difference that the energy consumption is low between 5PM and 8PM.

D) Adults working outside the home with school aged children. School aged children tend to be home for part of the summer, and when in school they tend to return home earlier than their parents. Thus, during the summer months these homes tend to see their air-conditioners turned on earlier than the homes without children (load profile B above).

Some of the simulated load profiles (for the summer months) are shown in Figure 2 (the load profile for working adults with school-aged children has not been included to improve the legibility of the illustration.) While our simulations divided the year into three seasons (Summer, Winter and Spring/Fall), Figure 2 includes only the Summer load profiles to declutter the illustration.

\section{Findings}

Table 1 summarizes the annual electricity bills for the hypothetical home with and without solar panels, and with and without battery storage under the different current rate plans for the four load profiles (NEM 2.0 tariffs from 2020 were used). To reduce the number of scenarios that we examine, we assume that the solar panels are installed facing south and that the array is sized to exactly match the annual electricity consumption of the household of $7411 \mathrm{kWh}$ (in other words the usage offset is 100\%). In Table 1 , the notations B and NB refer to the annual electricity bills with and without battery storage, respectively. The TOU D Prime rate plan is available as an option for customers who have electric vehicles

Table 1. Annual electricity bills for various rate plans with and without battery storage.

\begin{tabular}{|c|c|c|c|c|c|c|c|c|c|c|c|c|}
\hline \multirow{3}{*}{$\begin{array}{l}\text { Load } \\
\text { Profile }\end{array}$} & \multicolumn{4}{|c|}{ TOU 4-9 plan } & \multicolumn{4}{|c|}{ TOU 5-8 plan } & \multicolumn{4}{|c|}{ TOU D Prime plan } \\
\hline & \multicolumn{2}{|c|}{ Solar panels } & \multicolumn{2}{|c|}{ No solar } & \multicolumn{2}{|c|}{ Solar panels } & \multicolumn{2}{|c|}{ No solar } & \multicolumn{2}{|c|}{ Solar panels } & \multicolumn{2}{|c|}{ No solar } \\
\hline & B & NB & B & NB & B & NB & B & NB & B & NB & B & NB \\
\hline A & $\$ 169$ & $\$ 384$ & $\$ 1836$ & $\$ 2082$ & $\$ 198$ & $\$ 465$ & $\$ 1792$ & $\$ 2378$ & $\$ 218$ & $\$ 649$ & $\$ 1487$ & $\$ 2054$ \\
\hline B & $\$ 208$ & $\$ 418$ & $\$ 1856$ & $\$ 2095$ & $\$ 255$ & $\$ 545$ & $\$ 1828$ & $\$ 2137$ & $\$ 240$ & $\$ 660$ & $\$ 1487$ & $\$ 2045$ \\
\hline $\mathrm{C}$ & $\$ 179$ & $\$ 279$ & $\$ 1822$ & $\$ 1975$ & $\$ 213$ & $\$ 278$ & $\$ 1781$ & $\$ 1895$ & $\$ 218$ & $\$ 420$ & $\$ 1469$ & $\$ 1828$ \\
\hline $\mathrm{D}$ & $\$ 198$ & $\$ 406$ & $\$ 1852$ & $\$ 2090$ & $\$ 238$ & $\$ 496$ & $\$ 1816$ & $\$ 2099$ & $\$ 232$ & $\$ 649$ & $\$ 1486$ & $\$ 2040$ \\
\hline
\end{tabular}


or battery storage or heat pumps. Battery storage can be installed even without solar panels, in which case the system would store cheaper electricity from the grid during the daytime, and then use that stored energy later in the evening when the rates are higher. We have, therefore, included that option in the analysis below. Table 1 indicates that in all cases having battery storage (column B) results in lower annual electricity bills compared to not having battery storage (column NB).

Table 2 summarizes the payback period in years for battery installations under the different rate plans and load profiles. For this analysis we are exclusively looking at the payback period for the battery installation by looking at the marginal benefit of getting the battery installed. For example, a customer on the TOU 4-9 plan under load profile A would save $\$ 215.23$ per year by installing a Powerwall II battery which costs $\$ 9768$ after the federal tax credit. $\$ 9768$ divided by $\$ 215.23$ equals 45.38 years. As previously, we assume that the solar panels are installed facing south and that the array is sized to exactly match the annual electricity consumption of the household of $7411 \mathrm{kWh}$. What Table 2 clearly indicates is that under the current rate structure, battery storage is not a good investment for the average household when it is seen merely as a way of reducing annual electricity bills. The minimum payback period across the various load profiles and rate plans for the average household exceeds 17 years, well beyond the 10-year warrantied life of the battery!

Table 3 summarizes the payback period in years for battery installations under the different rate plans and load profiles for a household that has solar production and electricity consumption three times as much as for the household in Table 2. The calculations continue to assume that the system includes one Powerwall 2 battery. Even though the payback periods have decreased substantially,

Table 2. Payback period (years) for battery storage for the median household.

\begin{tabular}{ccccccc}
\hline \multirow{2}{*}{ Load Profile } & \multicolumn{2}{c}{ TOU 4-9 plan } & \multicolumn{2}{c}{ TOU 5-8 plan } & \multicolumn{2}{c}{ TOU D Prime plan } \\
\cline { 2 - 7 } & Solar panels & No solar & Solar panels & No solar & Solar panels & No solar \\
\hline A & 45.38 & 40.07 & 36.48 & 33.55 & 22.65 & 17.20 \\
B & 46.56 & 40.82 & 33.78 & 31.62 & 23.25 & 17.52 \\
C & 97.59 & 63.78 & 148.76 & 85.66 & 48.35 & 27.22 \\
D & 46.95 & 41.06 & 37.87 & 34.57 & 23.44 & 17.62 \\
\hline
\end{tabular}

Table 3. Payback period (years) for battery storage for a much larger household.

\begin{tabular}{ccccccc}
\hline \multirow{2}{*}{ Load Profile } & \multicolumn{2}{c}{ TOU 4-9 plan } & \multicolumn{2}{c}{ TOU 5-8 plan } & \multicolumn{2}{c}{ TOU D Prime plan } \\
\cline { 2 - 7 } & Solar panels & No solar & Solar panels & No solar & Solar panels & No solar \\
\hline A & 19.57 & 21.75 & 13.15 & 13.17 & 9.61 & 9.00 \\
B & 19.96 & 21.75 & 12.56 & 12.82 & 9.80 & 9.00 \\
C & 33.86 & 24.44 & 50.84 & 28.55 & 16.12 & 10.22 \\
D & 20.21 & 21.75 & 13.52 & 13.37 & 9.93 & 9.00 \\
\hline
\end{tabular}


battery storage is still not an attractive investment when it is seen merely as a way of reducing the annual electricity bill.

So, when do battery backup installations make sense? The recent extended electrical grid failure in Texas, and the constant threat of rolling power cuts in California during high wind events lead us to consider the benefit of battery storage (when coupled with solar panels) as a way of having electricity in the house for the essential uses during an extended grid failure. However, how do we assign a value to the convenience of having electricity to power the refrigerators and freezers, keep the lights burning, the air filters and CPAP machines running during an extended grid failure? One way to do this is by looking at the cost of alternate emergency power sources.

A small gasoline powered generator may cost only a few hundred dollars, but they are noisy, dependent on fossil fuels, need regular maintenance and resupply, and require the homeowner to run long extension cords from the generator to the essential loads. Further, they must be manually started. Solar generators (portable battery units into which portable solar panels can be plugged) are quiet, do not use fossil fuels to operate, and do not need much maintenance, but they too need to be manually started and require the homeowner to run long extension cords into the house for the essential loads. These portable battery units are available in various battery capacities and at various price points but most of these units are designed for portable use in recreational vehicles and do not have the capacity to meet even $25 \%$ of the average daily electrical energy use of the median sized house cited in this study (this house uses $7411 \mathrm{kWh}$ a year or an average of $20.3 \mathrm{kWh}$ a day.) One promising battery is the Bluetti EP500, a new $5.1 \mathrm{kWh}$ portable battery, which is expected to be priced around $\$ 3200$ when it comes to the market in the next few months. This battery is expected to provide $4360 \mathrm{kWh}$ of AC power from a full charge for an efficiency of approximately $85 \%$. Two of these Bluetti EP500 batteries would provide about $72 \%$ of the capacity of one Powerwall 2, or about $43 \%$ of the daily energy use of the median household cited in this paper. The cost of getting a manual transfer switch and portable solar panels to connect to this battery system would increase the cost of this installation to over $\$ 9000$. The grid tied solar panels that solar customers have cannot be connected to these batteries as per code. Further, these portable batteries do not qualify for the federal tax credit. With the price of this portable battery solution approaching the after tax credit installed cost of the Tesla Powerwall 2 and still falling significantly short of the Powerwall 2 in terms of functionality (for example the Powerwall 2 can automatically and seamlessly switch over to battery power during a grid failure which the portable battery solutions cannot), we conclude that customers who are in regions of the country where grid failures are common and who wish to have an electrical backup solution that is quiet, maintenance free and automatic, and which has enough capacity to power a large percentage of the daily energy usage of the household, should consider installing a battery storage system that is coupled to their solar 
panel array. Such a battery-coupled solar panel array system will provide homeowners peace of mind in knowing that their batteries will automatically kick in when the grid fails and with some judicious use, the home can remain powered indefinitely, if there are not too many cloudy days in a stretch.

\section{Conclusion}

Battery storage has often been suggested as a way for solar consumers on time-of-use rate plans to reduce their utility bills by storing the excess solar generated electricity in the batteries when rates are low, and then utilizing that energy to run the household loads later in the day when the rates are higher. In theory this seems to be a very sound proposition. But as our analyses show, battery storage solutions are difficult to justify financially solely to reduce utility bills. However, battery storage (when coupled with solar panels) may make sense in areas where regular grid failures and rolling black-outs are common and where the homeowner wishes to have a low noise, low maintenance, low carbon footprint, low intervention solution that can power a large portion of the home's electrical load during a sustained power outage.

\section{Limitations and Future Research}

While the data used in this study come from southern California, the conclusions are applicable to all of California. However, different states have different tariff structures, and a future paper could examine the economic viability of battery storage in other states within the United States and elsewhere. In our analysis of the economics of battery storage solutions we examined the cost savings (avoided costs in electrical utility bills) that a solar customer may enjoy by getting a battery installed. In calculating these savings, we used the current utility rates charged by SCE for customers under NEM 2.0. Will the new tariffs under NEM 3.0 (that is expected to go into force in 2022) change the economic viability of battery storage solutions? This should be studied once the NEM 3.0 program and tariffs are finalized. Ybarra, Broughton and Nyer (2021) have found some evidence for the claims made by the IOUs that solar panel installations under the current net metering program favor the wealthier customers and that this leads to an inequitable situation with non-solar customers shouldering the lion's share of the fixed costs incurred by the IOUs. NEM 3.0 is expected to be less beneficial to customers who go solar after NEM 2.0 ends. What impact will NEM 3.0 have on new residential solar panel installations starting 2022? Will, as many in the solar industry claim, an adverse NEM 3.0 program lead to a steep fall in the number of residential solar panel installations? Once again, this is something that should be examined in the future.

\section{Conflicts of Interest}

The authors declare no conflicts of interest regarding the publication of this paper. 


\section{References}

Distributed Generation Interconnection Program Data (2021). https://www.californiadgstats.ca.gov/downloads/

Nyer, P. U., Broughton, J. B., \& Ybarra, C. E. (2019). The Economics of Residential Solar Panel Installations for Customers on Tiered Rate Plans. Open Journal of Business and Management, 7, 1999-2008. https://doi.org/10.4236/ojbm.2019.74137

Nyer, P. U., Ybarra, C. E., \& Broughton, J. B. (2019). The Economics of Residential Solar Panels: Comparing Tiered and Time of Use Plans. Open Journal of Business and Management, 8, 56-67. https://doi.org/10.4236/ojbm.2020.81004

Southern California Edison (2021a). Energy Data: Reports and Compliance. https://www.sce.com/regulatory/energy-data---reports-and-compliances

Southern California Edison (2021b). Historical Prices and Rate Schedules. https://www.sce.com/regulatory/tariff-books/historical-rates

Ybarra, C. E., Broughton, J. B., \& Nyer, P. U. (2021). Trends in the Installation of Residential Solar Panels in California. Low Carbon Economy, 12. (Forthcoming) 